\title{
Therapeutic effect of bone cement injection in the treatment of intraosseous ganglion of the carpal bones
}

\author{
KUNLUN YU, XINZHONG SHAO, DEHU TIAN, JIANGBO BAI, BING ZHANG and YINGZE ZHANG
}

Department of Orthopedic Surgery, The Third Hospital of Hebei Medical University, Shijiazhuang, Hebei 050051, P.R. China

Received March 14, 2015; Accepted April 19, 2016

DOI: $10.3892 /$ etm.2016.3487

\begin{abstract}
The aim of the present study was to treat intraosseous ganglia of the carpal bones with injectable bone cement grafting. Between January 2012 and December 2013, 4 patients (3 men and 1 woman) presenting with wrist pain and activity limitation were diagnosed with intraosseous ganglion of the carpal bones by radiography. The patients were treated with minimal invasive curettage and bone cement injection surgery. All patients were followed up for a mean time of 17 months (range, 12-22 months). The wrist pain was significantly reduced in all patients following surgery. In addition, the activity range and grip strength were also improved compared with the preoperative parameters. Subsequent to treatment, the Mayo wrist score and the Disabilities of the Arm, Shoulder and Hand score presented mean values of 78.8 (range, 75-80) and 11 (range, 7.7-15.0), respectively. These results suggested that the patients showed a good recovery. All patients were satisfied with the postoperative results and returned to work within 4 weeks. In conclusion, bone cement injection is an effective and safe therapeutic strategy for the treatment of intraosseous ganglia of the carpal bone.
\end{abstract}

\section{Introduction}

Intraosseous ganglia within the carpal bones are relatively rare, with only a limited number of cases previously reported (1-3). They are benign, non-neoplastic bone lesions that have similar histological characteristics to those of soft tissue ganglion cysts $(4,5)$. The most common clinical symptom is wrist pain. Carpal bone cysts are one of the causes of chronic pain in the wrist joint; however, the etiology of cyst formation remains unknown (6-9). Single wrist intraosseous thecal cysts are most common in the lunate and scaphoid bones (9). In clinical treatment, tumor excision is the best strategy for painful ganglia, and is usually followed by autogenous bone grafting in the

Correspondence to: Professor Yingze Zhang, Department of Orthopedic Surgery, The Third Hospital of Hebei Medical University, 139 Ziqiang Road, Shijiazhuang, Hebei 050051, P.R. China

E-mail: yzzhang_77@163.com

Key words: bone cement, intraosseous ganglia, carpal bone traditional treatment $(10,11)$. However, the anatomical structure of the wrist joint is complicated, and thus the surgical incision may damage this structure, leading to multiple complications, including joint stiffness and disturbances of the fragile vascular system of the lunate bone (12).

Various artificial substances have been developed and used as bone grafting materials. For instance, bone cement is a grafting material with several advantages, including ease of handling, biological safety and sufficient compressive strength (6). Therefore, the present study used bone cement injection to treat 4 patients with intraosseous ganglia of the carpal bones and evaluated the therapeutic effects of this treatment.

\section{Patients and methods}

Patient description. The present study was approved by the Ethics Committee of the Third Hospital of Hebei Medical University (Shijiazhuang, China). Written informed consent was obtained from all patients. Between January 2012 and December 2013, 4 patients (3 men and 1 woman) presented at the Third Hospital of Hebei Medical University with wrist pain and activity limitation, and were diagnosed with intraosseous ganglion of the carpal bone by radiography. Briefly, X-rays and computed tomography (CT) scans showed that there were well-defined, round or oval bright defects surrounded by a circular sclerotic bone in the lunate bone, adjacent to the joint. In addition, magnetic resonance imaging (MRI) and Technetium-99m (T99) bone scans showed no cortical expansion, periosteal reaction or internal calcification. All these patients were treated by resection of the cyst, followed by injection of bone cement. Patients with secondary inflammation or degenerative joint disease were excluded from the study. Patient characteristics are shown in Table I.

Surgical procedure and postoperative care. Prior to surgery, patients received conservative treatment, including diclofenac sodium sustained-release tablets ( $75 \mathrm{mg}$ daily; Beijing Novartis Pharma Co., Ltd., Beijing, China) or celecoxib capsules (0.2 g daily; Pfizer Inc., New York, NY, USA), for 1 month. All patients were operated in the supine position, and local anesthesia or nerve tissue anesthesia was used. Anesthetic consisted of 2-4 ml Lidocaine (Shanghai Fosun Pharmaceutical Group Co., Ltd., Shanghai, China). The lesions were located in the lunate bone and thus the dorsal approach was adopted $(13,14)$. Guided by 
Table I. General information of the case series.

\begin{tabular}{lccccccc}
\hline $\begin{array}{l}\text { Patient } \\
\text { no. }\end{array}$ & $\begin{array}{c}\text { Age } \\
\text { (years) }\end{array}$ & Gender & $\begin{array}{c}\text { Lesion } \\
\text { side }\end{array}$ & $\begin{array}{c}\text { Pain duration } \\
\text { (months) }\end{array}$ & $\begin{array}{c}\text { Surgery } \\
\text { duration (min) }\end{array}$ & $\begin{array}{c}\text { Intraoperative } \\
\text { blood loss (ml) }\end{array}$ & $\begin{array}{c}\text { Follow-up } \\
\text { (months) }\end{array}$ \\
\hline 1 & 43 & Female & Left & 12 & 20 & 5 & 18 \\
2 & 33 & Male & Right & 8 & 30 & 10 & 15 \\
3 & 60 & Male & Right & 10 & 15 & 3 & 12 \\
4 & 42 & Male & Right & 18 & 16 & 4 & 22 \\
\hline
\end{tabular}

C-arm fluoroscopy, a guide pin was used to position the bone cyst location. Subsequent to performing a $2-\mathrm{mm}$ skin incision, the trocar was inserted into the skin until it reached the center of the cyst. Next, the trocar core with jelly-like liquid was removed from the cyst. A small drill was passed through the trocar to reach the cyst wall. Tissue was collected and used for histological analyses. Normal saline was used to flush the surgical position with a syringe, and $0.3 \mathrm{ml}$ bone cement (Mendec Spine; Tecres Medical, Verona, Italy) was then injected into the cavity. When the bone cement was completely solidified, the sleeve needle was pulled out, with no bone cement leakage observed. The skin wound was immediately bound, and the patients began flexion exercises from the next day following the surgery.

Histological analysis of tissues specimens. The collected tissues specimens were fixed for $24 \mathrm{~h}$ in $10 \%$ formalin and paraffin-embedded. Subsequently, serial sections of $4-\mu \mathrm{m}$ thickness were cut, dewaxed and stained with hematoxylin and eosin, prior to analysis under a microscope. These sections were used to confirm the pathology.

Postoperative management. At 1 day after the surgery, patients were able to perform finger flexion exercises, and 1 week later, patients were able to perform wrist flexion and extension functional exercises. Postoperative X-ray examination was performed in the outpatient service at 1, 3, 6, 12 and 18 months after surgery. CT scanning was also performed in the last follow-up. Patients were free to return to work when their wrist was able to bear the work intensity.

Evaluation. The following preoperative and postoperative results were recorded by independent observers: Pain value (1 to 10) was measured using the visual analog scale (VAS) system (15); hand strength was determined based on the lateral force (percentage of the contralateral force); wrist flexion extension was measured with a protractor; Mayo Wrist Score (MWS) (16); and the Disabilities of the Arm, Shoulder and Hand (DASH) score (17).

\section{Results}

Patient details. The patients participating in the present study included 3 males and 1 female, aged between 33 and 60 years (mean age, 44.5 years; Table I). In 3 of the patients, the lesion was in the right side, while in 1 case the lesion was located in the left side, and no patient presented a bilateral lesion. All the patients were subjected to X-ray examination due to the effect of wrist joint pain on daily activities. Patients with a history of trauma, local infection or neurovascular lesions were excluded from the current study. The pain duration was between 8 and 18 months before admission, with a mean duration of 12 months. Conservative treatments, including plaster fixation and nonsteroidal drugs, did not relieve the symptoms. The ranges of motion of wrist flexion and extension were limited in all patients, and their grip strength was reduced compared with that of the healthy wrist. Histological analyses to confirm the pathology were performed prior to surgery for 3 patients; however, the tissue sample was too small for a pathological diagnosis in 1 patient. For the 3 cases, destruction in the internal capsule wall of the carpal bone was significant such that the integrated capsule wall structure could not be observed.

Preoperative imaging. In the four patients included in the present study, preoperative CT scans demonstrated that the cysts were located within the bone analogous central region, and no cortical bone destruction was observed (Fig. 1A and B) Furthermore, preoperative X-ray examinations revealed that the lesions in all patients had a well-defined, round and osteolytic low density area with sclerosing edge; however, the degree of sclerosis was not the same for all patients (Fig. 1C and D). All lesions were located at the lunate bone.

Surgical treatment and follow-up. The mean surgery duration for all 4 patients was $20 \mathrm{~min}$ (range, 15-30 $\mathrm{min}$ ), with a mean blood loss amount of $5.5 \mathrm{ml}$ (range, 3-10 ml) during the surgery. Postoperatively, the wounds healed well in all patients. The mean follow-up time was 16.8 months (range, 12-22 months). Wrist pain symptoms disappeared following surgery, and 3 of the patients presented increased grip strength at the 24-month follow-up. In all cases, increased wrist flexion and extension range were reported in the wrist joint, which are presented as mobility in Table II. Bone cement absorption was not observed by CT examination during the follow-up period (Fig. 1E and F), although X-ray scans suggested that bone absorption had occurred (Fig. $1 \mathrm{G}$ and $\mathrm{H}$ ). In addition, T99 bone scans showed that partial absorption of bone cement in the lunate bone was increased, without absorption of bone cement in other parts of the carpal bone (Fig. 2). Furthermore, no tumor recurrence, rejection reaction or other complications were reported during the follow-up, and all patients returned to work within 4 weeks.

VAS score, MWS and DASH score results. The present study evaluated the pain that patients experienced based on their VAS scores, as well as the grip strength of all patients (Table II). At 12 months postoperatively, the mean 

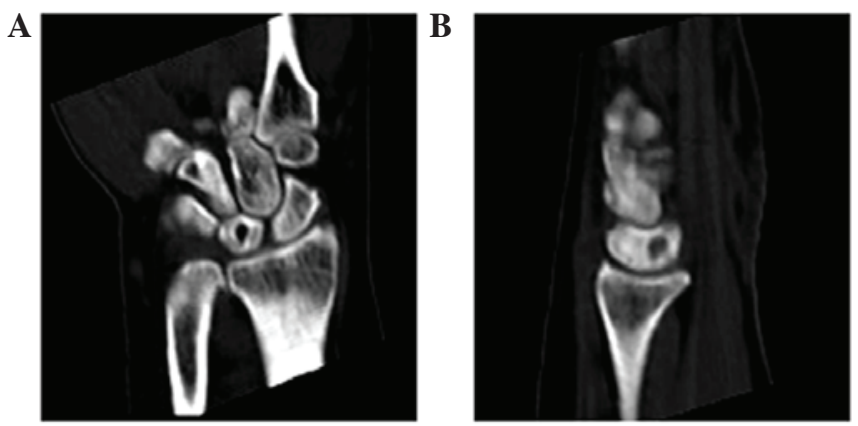

C
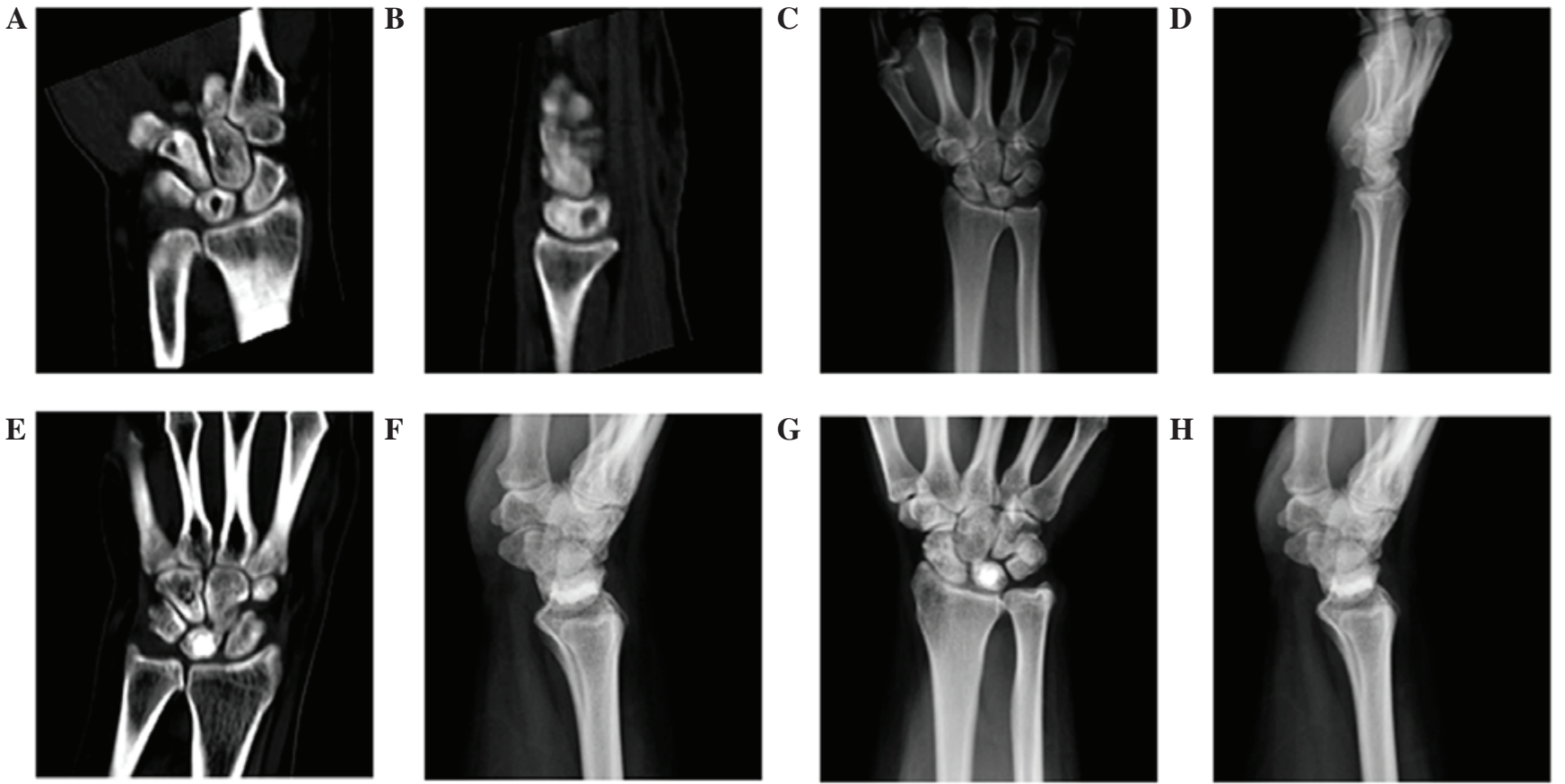

Figure 1. Representative case of a 43-year-old female with an intraosseous ganglion of the carpal bone. Preoperative (A and B) CT scans and (C and D) X-ray scans. Postoperative (12 months) (E and F) CT scans and (G and H) X-ray scans.

VAS score was 0.3 (range, $0-1$ ), indicating that the pain experienced by patients was reduced, when compared with the preoperative pain, with a mean VAS score of 7.8 (range, 7-8). Similarly, the mean strength score improved from 39.3 (range, 32-46) preoperatively to 87.5 (range, 82-91) postoperatively. Following treatment, the mean MWS and DASH score reached 78.8 (range, 75-80) and 11 (range, 7.7-15.0), respectively (Table II). All the patients were satisfied with the treatment, and the aforementioned results suggested a good recovery in all cases.

\section{Discussion}

Ganglia can be observed in various anatomic locations, including the metaphysis adjacent to the growth plate of the tubular bones; in particular, the humerus and femur. Ganglia may be classified as intraosseous, subperiosteal, intraarticular or soft tissue ganglia. Soft tissue ganglia are commonly observed, occasionally presenting with superficial erosion and close proximity to the bone; however, their intraosseous counterparts have been rarely reported $(18,19)$. In the majority of patient cohorts, intraosseous ganglia are most commonly detected in the lower extremities, particularly in the tibia and femur, and predominantly occur in the epiphyseal-metaphyseal area of the long tubular bones (20). Benign or malignant tumors are rare in carpal bones, with intraosseous ganglion being the most common type at this site (7).

The cause of the intraosseous ganglia development remains unclear. Two main types have been suggested, including the idiopathic or primary type (lesion possibly formed due to a degenerative bone process) and the secondary type (lesion caused by the cortical penetration of a previously existing soft tissue ganglion) (2,21). Kambolis et al (22) have previously suggested that ganglionic cysts of the bone developed by

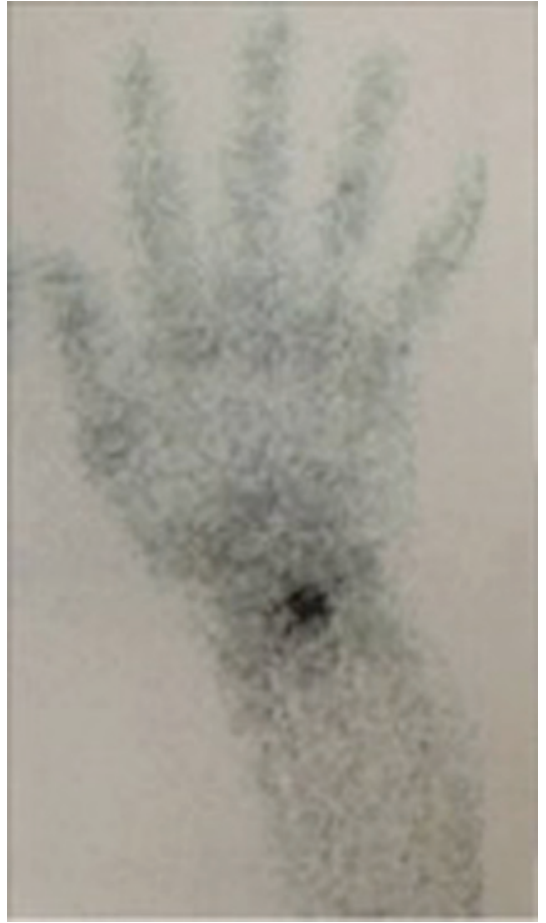

Figure 2. Postoperative T99 bone scans showed that partial absorption of bone cement in the lunate bone was increased, without absorption of bone cement in other parts of the carpal bone. T99, Technetium-99m.

invasion of the ganglion-like connective tissue into the bone from the local soft parts. In addition, Schajowicz et al (23) stated that $\sim 85 \%$ of the reported cases are of intraosseous origin associated with altered mechanical stress leading to intramedullary vascular disturbance and aseptic necrosis.

Intraosseous ganglion is one of the most frequent lytic defect of the wrist. Its location in the lunate bone is frequently 
Table II. Preoperative and postoperative evaluation of the patients.

\begin{tabular}{|c|c|c|c|c|c|c|c|c|c|}
\hline \multirow[b]{2}{*}{ Patients } & \multicolumn{2}{|c|}{ Pain on VAS } & \multicolumn{2}{|c|}{$\begin{array}{c}\text { Grip strength } \\
\text { (\% of healthy wrist) }\end{array}$} & \multicolumn{2}{|c|}{$\begin{array}{c}\text { Mobility } \\
\text { (\% of healthy wrist) }\end{array}$} & \multirow[b]{2}{*}{ MWS } & \multirow{2}{*}{$\begin{array}{l}\text { DASH } \\
\text { score }\end{array}$} & \multirow{2}{*}{$\begin{array}{c}\text { Patient } \\
\text { satisfaction }\end{array}$} \\
\hline & Pre & Post & Pre & Post & Pre & Post & & & \\
\hline 1 & 8 & 0 & 37 & 91 & 40 & 70 & 80 & 7.7 & Satisfied \\
\hline 2 & 7 & 1 & 42 & 87 & 38 & 66 & 75 & 12.8 & Satisfied \\
\hline 3 & 8 & 0 & 32 & 90 & 50 & 75 & 80 & 8.5 & Satisfied \\
\hline 4 & 8 & 0 & 46 & 82 & 45 & 80 & 80 & 15.0 & Satisfied \\
\hline Mean & 7.8 & 0.3 & 39.3 & 87.5 & 43.3 & 72.8 & 78.8 & 11.0 & \\
\hline
\end{tabular}

Postoperative pain, strength and mobility, as well as the MWS, DASH score and patient satisfaction score, were evaluated at the 12-month follow-up. VAS, visual analog scale; MWS, Mayo Wrist Score; DASH, Disabilities of the Arm, Shoulder and Hand.

discovered by chance on an X-ray scan performed for another condition, or due to wrist pain, and very rarely due to a lunate fracture.

X-ray films, CT and MRI examinations help reach the diagnosis of intraosseous ganglia. Radiographs and CT scans typically show eccentrically located, well-defined, rounded or ovoid lucent defects with a surrounding zone of sclerosis adjacent to the articular surface $(24,25)$. No expansion of the cortex, periosteal reaction or internal calcification are observed, and these features can help to distinguish between the intraosseous ganglion and numerous other lesions, such as degenerative cysts, giant cell tumors and osteoid osteomas (26). The joint space is normal in all intraosseous ganglia, while certain lesions present a communication in particular with the scapholunate joint $(24,25)$. CT and MRI assist in the clarification of the extent of the abnormality and allow for more accurate preoperative planning. In specific lesions, an intraarticular extension may be visible in association with the defect in the surface of the lunate upon MRI examination $(24,25)$.

The lunate bone has a central position in the wrist. Surgery on the lunate bone can be performed in either the dorsal or palmar position. The palmar anatomical structure is relatively complex and its location is relatively deep. Furthermore, the median nerve that is found in the carpal tunnel may be disrupted when performing in the palmar position (27). Conversely, the dorsal approach is performed in a superficial location, in which only an extensor tendon is located (27). Therefore, in order to reduce the occurrence of complications during the treatment of intraosseous ganglia, we recommend a dorsal approach surgery.

Following resection, the ganglion cyst cavity within the lunate bone should be filled to avoid bone fractures caused by the axial pressure (28). Bone cement is a type of biological bone substitute materials that has been applied in clinical treatment for years, and is particularly suitable for the repair of bone defects subsequent to resection of bone tumor $(29,30)$. The traditional treatment strategy for carpal bone cyst with persistent symptoms is treatment by open lesion scraping, followed by autogenous bone transplantation, which severely limits the daily activities of patients $(2,3)$. Although this treatment can improve the patients' clinical symptoms, several studies have reported that, after surgery, $\sim 40 \%$ of patients still present symptoms that influence their daily life or have a limited flexibility of flexion and extension activities $(7,9)$. Certain studies $(31,32)$ have applied resection of the lunate bone cyst and bone graft under wrist arthroscopy-assisted minimally invasive surgery for reducing the complications caused by incision surgery. However, the surgical technology requirements for the wrist joint are relative high, since the corresponding equipment is necessary, which limits its application. In our previous study, balloon dilatation-based bone cement was successfully applied to the treatment of ischemic lunate bone necrosis using vertebroplasty and bone cement conveying equipment (33). Bone cement injection has certain limitations, since it is not suitable for the removal of a damaged cyst, with the exception of the dorsal cortex and outer residual cortex, since it may cause bone cement leakage to the wrist joint cavity. Therefore, CT preoperative evaluation is essential.

The incision made during percutaneous surgery is small, thus it is not possible to fully reveal and scrape the lunate bone cyst, cystic wall and its contents, which results in difficulties obtaining material for pathologic examination. In the present study, pathological examination was performed in 3 patients, but it was not possible in 1 case since the sample was too small for pathological diagnosis. Upon pathologic examination in the 3 cases, the destruction in the internal capsule wall of carpal bone was large, thus the integrated capsule wall structure could not be obtained.

The recurrence of ganglion cysts in the foot inner bone following surgical resection rate has been reported to be $\sim 6.1 \%$; however, no recurrence has been previously reported within the carpal bones ganglion cyst following surgery (34). It has been suggested that recurrences do not necessarily develop due to inadequate excision or curettage, but may occur in conjunction with the connective tissue metaplasia at the operative site or in tissue immediately adjacent to it $(2,35)$. In the present study, no recurrence was detected during follow-up.

A balloon kyphoplasty instrument is typically used for cyst curetting and injection of bone cement; however, it is not suitable for lunate bone cysts. Based on the early curative effect, there is a need to further improve the surgical instruments. Due to the small number of cases and the short period of follow-up in the present study, the long-term efficacy of this procedure requires further assessment. Since the present 
study used the technique to treat a carpal lunate bone cyst, it is unclear whether this technique would be suitable for other wrist cysts, and this requires further clinical research.

In conclusion, the results of the present study suggested that bone cement injection is an effective and safe therapeutic strategy for the treatment of intraosseous ganglion of the carpal bone.

\section{Acknowledgements}

The present study was supported by a grant from the Key Project of Medical Research of Hebei Province (no. ZL20140209).

\section{References}

1. Dumas $\mathrm{P}$, Georgiou C, Chignon-Sicard B, Balaguer T, Lebreton $\mathrm{E}$ and Dumontier C: Intra-osseous ganglion cyst of the carpal bones. A review of the literature underlining the importance of systematic computed tomography. Chir Main 32: 3-7, 2013 (In French).

2. Logan SE, Gilula LA and Kyriakos M: Bilateral scaphoid ganglion cysts in an adolescent. J Hand Surg Am 17: 490-495, 1992.

3. Arabori M, Kitazawa H, Akisue T, Kuroda R, Fujioka H, Doita M and Kurosaka M: Intraosseous ganglion of the phalanx. Clin Imaging 32: 73-76, 2008

4. Warren NP and Harris NH: Juxta-articular aneurysmal bone cyst. J R Soc Med 81: 291-292, 1988.

5. Barth E and Hagen R: Juxta-articular bone cyst. Acta Orthop Scand 53: 215-217, 1982.

6. Yajima H, Murata K, Kawamura K, Kawate K and Takakura Y Treatment of intraosseous ganglia and bone cysts of the carpal bones with injectable calcium phosphate bone cement. Hand Surg 13: 167-173, 2008

7. Waizenegger M: Intraosseous ganglia of carpal bones. J Hand Surg Br 18: 350-355, 1993

8. Schacherer TG and Aulicino PL: Intraosseous ganglia of the carpal bones. Orthop Rev 20: 889-892, 1991.

9. Tham S and Ireland DC: Intraosseous ganglion cyst of the lunate: Diagnosis and management. J Hand Surg Br 17: 429-432, 1992.

10. Kligman M and Roffman M: Bilateral intraosseous ganglia of the scaphoid and lunate bones. J Hand Surg Eur Vol 22: 820-821, 1997.

11. Matsumine A, Kusuzaki K, Matsubara T, Okamura A, Okuyama N, Miyazaki S, Shintani K and Uchida A: Calcium phosphate cement in musculoskeletal tumour surgery. J Surg Oncol 93: 212-220, 2006.

12. Daly PJ, Sim FH, Beabout JW and Unni KK: Intraosseous Ganglion Cysts. Orthopedics 11: 1715-1719, 1988.

13. Trail IA, Murali R, Stanley JK, Hayton MJ, Talwalkar S, Sreekumar R and Birch A: The long-term outcome of four-corner fusion. J Wrist Surg 4: 128-133, 2015.

14. Bhatia DN: Direct "Cystoscopic" Approach for Arthroscopic Decompression of an Intraosseous Ganglion of the Lunate. Arthrosc Tech 4: e223-e229, 2015.

15. Huskisson EC: Measurement of pain. Lancet 2: 1127-1131, 1974.
16. Amadio PC, Berquist TH, Smith DK, Ilstrup DM, Cooney WP 3rd and Linscheid RL: Scaphoid malunion. J Hand Surg Am 14: 679-687, 1989.

17. Hudak PL, Amadio PC and Bombardier C: Development of an upper extremity outcome measure: The DASH (disabilities of the arm, shoulder and hand)[corrected]. The Upper Extremity Collaborative Group (UECG). Am J Ind Med 29: 602-608, 1996.

18. Williams HJ, Davies AM, Allen G, Evans N and Mangham DC: Imaging features of intraosseous ganglia: A report of 45 cases. Eur Radiol 14: 1761-7169, 2004.

19. Angelides AC: Ganglions of the hand and wrist. In: Green's Operative Hand Surgery. 3rd edition Green DP (ed). Churchill Livingstone, New York, pp2159-2162, 1993.

20. Helwig U, Lang S, Baczynski $M$ and Windhager R: The intraosseous ganglion. A clinical-pathological report on 42 cases. Arch Orthop Trauma Surg 114: 14-17, 1994.

21. Lorente R, Moreno M and Quiles M: Bilateral intraosseous ganglia of the lunate: A case report. J Hand Surg Am 17: 1084-1085, 1992.

22. Kambolis C, Bullough PG and Jaffe HI: Ganglionic cystic defects of bone. J Bone Joint Surg Am 55: 496-505, 1973.

23. Schajowicz F, Clavel Sainz M and Slullitel JA: Juxta-articular bone cysts (intra-osseous ganglia): A clinicopathological study of eighty-eight cases. J Bone Joint Surg Br 61: 107-116, 1979.

24. Haller J, Resnick D, Greenway G, Chevrot A, Murray W, Haghighi P, Sartoris DJ and Chen CK: Juxtaacetabular ganglionic (or synovial) cysts: CT and MR features. J Comput Assist Tomogr 13: 976-983, 1989.

25. Benis $\mathbf{J}$ and Turpin F: The role of imaging in the assessment of vascularity at hand and wrist. Chir Main 29 (Suppl 1): S21-S27, 2010 (In French)

26. Ferkel RD, Field J, Scherer WP, Bernstein ML and Kasimian D: Intraosseous ganglion cysts of the ankle: A report of three cases with long-term follow-up. Foot Ankle Int 20: 384-388, 1999.

27. Van den Dungen S, Marchesi S, Ezzedine R, Bindou D and Lorea P: Relationship between dorsal ganglion cysts of the wrist and intraosseous ganglion cysts of the carpal bones. Acta Orthop Belg 71: 535-539, 2005.

28. Uriburu IJ and Levy VD: Intraosseous ganglia of the scaphoid and lunate bones: Report of 15 cases in 13 patients. J Hand Surg Am 24: 508-515, 1999.

29. Guo H, Wei J and Liu CS: Development of a degradable cement of calcium phosphate and calcium sulfate composite for bone reconstruction. Biomed Mater 1: 193-197, 2006.

30. Stubbs D, Deakin M, Chapman-Sheath P, Bruce W, Debes J, Gillies RM and Walsh WR: In vivo evaluation of resorbable bone graft substitutes in a rabbit tibial defect model. Biomaterials 25: 5037-5044, 2004.

31. Ashwood N and Bain GI: Arthroscopically assisted treatment of intraosseous ganglions of the lunate: A new technique. J Hand Surg Am 28: 62-68, 2003.

32. Bain GI, Turner PC and Ashwood N: Arthroscopically assisted treatment of intraosseous ganglions of the lunate. Tech Hand Up Extrem Surg 12: 202-207, 2008.

33. Chen W, Wang J, Pan J, Zhang Q, Shao X and Zhang Y: Primary results of Kienböck's disease treated using balloon kyphoplasty system. Arch Orthop Trauma Surg 132: 677-683, 2012.

34. Murff R and Ashry HR: Intraosseous ganglia of the foot. J Foot Ankle Surg 33: 396-401, 1993.

35. Pellegrino EA and Olson JR: Bilateral carpal lunate ganglia. Clin Orthop Relat Res 87: 225-227, 1972. 